\title{
Estrogen Inhibits the Response-to-Injury in a Mouse Carotid Artery Model
}

\author{
Theodore R. Sullivan, Jr., ${ }^{\star \star}$ Richard H. Karas, ${ }^{*}$ Mark Aronovitz, ${ }^{\star}$ Garrey T. Faller, ${ }^{\S}$ Jeff P. Ziar, ${ }^{\S}$ John J. Smith, * \\ Thomas F. O'Donnell, Jr., ${ }^{*}$ and Michael E. Mendelsohn* \\ ${ }^{*}$ Molecular Cardiology Research Center and Cardiology Division, Department of Medicine; ${ }^{\ddagger}$ Department of Vascular Surgery; and \\ ${ }^{\S}$ Department of Pathology, New England Medical Center and Tufts University School of Medicine, Boston, Massachusetts 02111
}

\begin{abstract}
The atheroprotective effects of estrogen are well documented, but the mechanisms responsible for these effects are not well understood. To study the role of physiologic (nanomolar) estrogen levels on the arterial response-to-injury, we applied a mouse carotid artery injury model to ovariectomized C57BL/6J mice. Mice were treated with vehicle $(-E 2, n=10)$ or $17 \beta$-estradiol $(+E 2, n=10)$ for $7 \mathrm{~d}$, subjected to unilateral carotid injury, and $14 \mathrm{~d}$ later contralateral (normal $=\mathrm{NL}$ ) and injured carotids from $-\mathrm{E} 2$ and +E2 animals were pressure fixed, harvested, and analyzed by quantitative morphometry. E2 levels in +E2 mice were consistently in the nanomolar range (2.1-2.5 $\mathrm{nM}$ ) at days 0,7 , and 14. At $14 \mathrm{~d}$, measures of both intimal and medial area were markedly increased in the -E2 group: ( $-\mathrm{E} 2$ vs NL, $P<0.05$ for both), but were unchanged from normal levels in the + E2 group $(+E 2$ vs NL, $P=$ NS and $+E 2$ vs $-E 2, P<0.05$ for both). Cellular proliferation, as assessed by bromodeoxyuridine (BrdU) labeling, was significantly increased over NL in the -E2 mice, but this increase was markedly attenuated in the estrogen replacement group ( total BrdU positive cells/section: $\mathrm{NL}=6.4 \pm 4.5 ;-\mathrm{E2}$ $=113 \pm 26,+\mathrm{E} 2=40 \pm 3.7 ;-\mathrm{E} 2$ vs $\mathrm{NL}, P<0.05 ;+\mathrm{E} 2$ vs NL, $P=\mathrm{NS} ;-\mathrm{E} 2$ vs $+\mathrm{E} 2, P<0.05)$. These data $(a)$ demonstrate significant suppression of the mouse carotid response-to-injury by physiologic levels of estrogen replacement; $(b)$ support the utility of this model in the study of the biologic effects of estrogen on the vascular-injury response; and $(c)$ suggest a direct effect of estrogen on vascular smooth muscle cell proliferation in injured vessels. (J. Clin. Invest. 1995. 96:2482-2488.) Key words: vascular smooth muscle - atherosclerosis • steroid hormones • C57BL/6J mice • carotid artery
\end{abstract}

Address correspondence to Michael E. Mendelsohn, Molecular Cardiology Research Center, New England Medical Center, 750 Washington Street, Box 80, Boston, MA 02111. Phone: 617-636-1440; FAX: 617636-1444.

Received for publication 3 May 1995 and accepted in revised form 10 August 1995.

J. Clin. Invest.

(C) The American Society for Clinical Investigation, Inc.

0021-9738/95/11/2482/07 \$2.00

Volume 96, November 1995, 2482-2488

\section{Introduction}

The atheroprotective effects of estrogen in women are supported by a variety of epidemiologic and observational studies (reviewed in references 1-4), but the mechanisms responsible for these effects are not well understood. The beneficial effects of estrogen on atherosclerosis are thought to involve both effects of estrogen on systemic factors that influence atherogenesis, as well as direct effects of estrogen on vascular cells $(3,5-8)$. Direct effects of estrogen on vascular cells include both rapid, nongenomic effects of estrogen on vascular tone, and inhibitory effects of estrogen on the development and progression of atherosclerosis that are presumed to involve estrogen receptormediated effects of the hormone on gene transcription and cell growth in vascular cells (reviewed in reference 8 ). Recent studies in both primates $(9,10)$ and humans $(11,12)$ show that estrogen can alter vasomotor tone rapidly, which may involve the estrogen-stimulated release of preformed vasoactive substances from endothelium and/or smooth muscle, or a direct effect of estrogen on arterial smooth muscle cells (8). Evidence also suggests that longer term effects of estrogen may contribute to the atheroprotective effects of the steroid. For example, estrogen also may modulate basal release of vasodilators from the vessel wall by upregulating genes for rate-limiting enzymes in the biosynthesis of vasodilators such as prostacyclin and nitric oxide (13-15). Estrogen also affects the expression of other genes in vascular tissue, some of which may be important in cell cycle regulation $(8,16-17 a)$.

Estrogen-mediated inhibition of atherosclerosis in cholesterol-fed chicks was first demonstrated over $40 \mathrm{yr}$ ago (18), and numerous animal studies since, using a variety of models, have suggested that estrogen can inhibit proliferation of vascular cells in atherosclerotic lesions (19-22). In cultured vascular cells and tissue, $17 \beta$-estradiol (E2) ${ }^{1}$ also has been reported to inhibit the growth of vascular smooth muscle cells derived from rabbit aorta (23), and porcine coronary artery (24). However, interpretation of the effects of estrogen on atherogenesis and vascular cell growth in previous studies is complicated by the use of supraphysiologic (micromolar) estrogen dosing, atherogenic (high cholesterol) diets, and/or the absence of measured levels of circulating hormone. The present study evaluates the carotid response-to-injury in ovariectomized female mice maintained on a normal diet for $3 \mathrm{wk}$, and given vehicle or physiologic levels of estrogen replacement. The data demonstrate sig-

1. Abbreviations used in this paper: BrdU, 5-Bromo-2'deoxyuridine; E2, estradiol; NL, normal. 
nificant suppression of the vascular response-to-injury under these conditions.

\section{Methods}

Animals. C57BL/6J mice (Charles River Laboratories, Kingston, NY) were used both in pilot studies and in the main study. For the latter, 25 -gram female mice were obtained $7 \mathrm{~d}$ after bilateral ovariectomy. All mice were maintained on normal, unsupplemented small animal chow (Regular Rodent Chow; Prolab, Syracuse, NY). C57BL/6J mice were chosen for these studies for three reasons: $(a)$ C57BL/6J are routinely used by our transgenic facility to create transgenic mice; $(b)$ C57BL/ 6J mice were used previously to create estrogen receptor-deficient transgenic mice (25), which are to be used in subsequent studies; and (c) C57BL/6J are known to have normal (low) circulating levels of lipoproteins on diets such as the one used in this study $(26,27)$. Five animals were housed per cage at $24^{\circ} \mathrm{C}$ in a room illuminated in 12-h light-dark cycles, with free access to food and water. All animals were monitored by the New England Medical Center Animal Facility staff, which includes a licensed veterinarian, in full compliance with the PHS animal welfare policy and the American Association for the Accreditation of Laboratory Animal Care. 17 $\beta$-E2, propylene glycol, and 5bromo-2'-deoxyuridine (BrdU) used in animal studies were obtained from Sigma Chemical Co. (St. Louis, MO).

Estrogen dosing. Pilot studies were performed first to determine the appropriate daily dose and length of time needed to attain steady state physiologic levels of E2 in the C57BL/6J mice. In these pilot studies, six mice received $0.1-\mathrm{ml}$ subcutaneous injections daily of either vehicle alone (propylene glycol), or E2 at $10 \mu \mathrm{g} / \mathrm{d}$ or $100 \mu \mathrm{g} / \mathrm{d}$. Blood samples in pilot studies and the main study were obtained by tail cut at the same time each day and just before any scheduled E2 injection. Blood was also collected for E2 measurements from normal, nonovariectomized C57BL/6J mice and premenopausal human volunteers. An additional parallel study using identical conditions and E2 dosing was used to evaluate the effect of E2 on circulating lipid levels. For the main experiment, 20 ovariectomized mice were divided into two groups and injected daily for $21 \mathrm{~d}$ day -7 to day +14 with either E2 $(+E 2,100 \mu \mathrm{g} / \mathrm{d})$, or vehicle alone (-E2). Blood samples were collected for E2 measurements from five mice on days $-7,0$, and 7 and from nine mice on day 14.

Estradiol immunoassay and lipid measurements. Circulating E2 levels were measured using a commercially available estradiol enzymelinked immunoassay (estradiol ELISA, Cayman Chemical Co., Inc., Ann Arbor, MI), according to the manufacturer's instructions. A standard curve was included with all assays, and concentrations of E2 were determined and expressed in nanomoles per liter (nM). Cholesterol and triglyceride levels were measured in microtitre assays using enzymatic methods, as described previously (28).

Carotid artery injury. All surgery was done by a vascular surgery fellow (T. R. Sullivan, Jr.) assisted by an experienced animal technician (M. Aronovitz) using a dissecting microscope (Zeiss, Oberkochen, Germany) at a magnification of 24 . The recently described mouse carotid injury method of Lindner et al. was used (29), with minor modifications. In brief, on day 0, animals were anesthetized with Nembutal (Abbott Laboratories, North Chicago, IL), and ketamine (Ketaset, Fort Dodge, IO) (0.04 mg per gram for each), and the left external carotid artery (LECA) was looped proximally and ligated distally with 7-0 silk suture (Ethicon, Somerville, NJ). Additional 7-0 silk ties were used to loop the common and internal carotid arteries for temporary vascular control during the procedure. A transverse arteriotomy was made in the LECA and a 0.35 -mm flexible angioplasty wire (No. 22339M; Advanced Cardiovascular Systems, Inc., Temecula, CA) was passed to the aortic arch $(\sim 1 \mathrm{~cm})$ and withdrawn three times with a rotating motion, with care taken to use the identical injury procedure for each animal. The wire was removed, the proximal LECA silk secured, and the incision closed with a running 5-0 nylon suture (Ethicon). At the time of carotid injury, osmotic minipumps (No. 2002; Alza Corp., Palo Alto, CA) loaded with $\mathrm{BrdU}(25 \mathrm{mg} / \mathrm{kg}$ per $\mathrm{d})$ were inserted through a small mid-back incision, which was closed as above. Animals were returned to appropriate cages and allowed to awaken under a warming lamp (average duration of anesthesia, 1-2 h). Before embarking on the main study, the carotid injury method was practiced on eight animals both to develop the method in our hands and to verify histologically that reproducible injury (complete deendothelialization) was obtained, as reported (29) (data not shown).

Tissue harvest and histology. $14 \mathrm{~d}$ after carotid injury (study day 14), animals were reanesthetized and killed by placement of a 22 -gauge butterfly angiocatheter in the left ventricle and in situ constant pressure fixation $(100 \mathrm{mmHg}$ ) with $4 \%$ paraformaldehyde in $0.1 \mathrm{M}$ phosphate buffer, $\mathrm{pH}$ 7.3. Both right and left common carotid arteries were harvested and divided into three experimental groups: uninjured normal (NL) $(n=20: 10-\mathrm{E} 2,10+\mathrm{E} 2)$, injured $-\mathrm{E}_{2}(n=10)$, and injured $+\mathrm{E}_{2}(n=10)$. Each artery was imbedded in paraffin, assigned a number and sections were cut from the proximal, middle, and distal thirds of the vessel. Parallel sections were subjected to both standard hematoxylin and eosin and elastin staining, as well as to immunocytochemical studies. All staining and subsequent analyses were done in a fully blinded fashion.

Morphometry. Morphometric analyses were performed in duplicate by blinded observers on elastin stained tissue. Vessel dimensions were measured at a magnification of 200 using a digitized tablet interfaced to a personal computer and the public domain National Institutes of Health Image Analysis program (30). For each artery section, four types of measurements were made: luminal area, area inside the innermost elastic lamina, area inside the adventitial (outermost) elastic lamina, and medial and intimal thickness. The area of the media was calculated by subtracting the measured area inside the innermost internal elastic lamina from the area within the outermost elastic lamina. Similarly, the area of the intima was calculated by subtracting the luminal area from the area inside the first internal elastic lamina. To calculate medial thickness, for each vessel cross section the linear distance between outermost and innermost elastic laminae was measured independently in four places (each $90^{\circ}$ apart) and averaged. Intimal thickness was measured similarly by measuring the distance between the innermost internal elastic lamina and the lumen.

BrdU labeling and immunocytochemistry. Immunohistochemical stains were performed using the following antisera and dilutions: BrdU (monoclonal anti-mouse, 1:100; Becton Dickinson, San Jose, CA), $\alpha$ smooth muscle actin (monoclonal anti-mouse, 1:500; Sigma Immunochemicals, St. Louis, MO), and factor VIII-related antigen (polyclonal anti-rabbit, 1:1,000; Incstar Corp., Stillwater, MN) (31-34).

Immunoperoxidase staining was performed using commercially available reagents (Vector Elite Avidin Biotin Complex (ABC) kit, PK6100; Vector Laboratories, Inc., Burlingame, CA) (35). All sections were deparafinized with xylene for $10 \mathrm{~min}$ and rehydrated with a series of graded ethanols $(100,90$, and $80 \%)$, each for $10 \mathrm{~min}$. Slides then were washed in distilled water for 5 mins, and endogenous peroxidases were blocked with $0.3 \%$ hydrogen peroxide in methanol for $30 \mathrm{~min}$ Slides were washed again in distilled water for $5 \mathrm{~min}$ and then immersed in $0.01 \mathrm{M}$ citrate buffer $(\mathrm{pH}=6)$ and microwaved twice for $5 \mathrm{~min}$ at high power, separated by a 5 -min cooling interval $(32,36)$. After a 5 20-min cooldown period, slides were washed in PBS and nonspecific binding sites were blocked with dilute horse or goat serum ( $2 \%$ in PBS) for $30 \mathrm{~min}$, depending upon the nature of the subsequent antibody Excess blocking serum was drained without washing, and primary antibodies were added and incubated overnight at $4^{\circ} \mathrm{C}$. For BrdU immunostaining, dilute $\mathrm{BrdU}$ primary antibody premixed with $2 \%$ dilute horse serum in PBS was then added to the slides, incubated for $1 \mathrm{~h}$ at $37^{\circ} \mathrm{C}$ and then overnight at $4^{\circ} \mathrm{C}$

The following day slides were washed with PBS for $2 \mathrm{~min}$ and then incubated at room temperature for $1 \mathrm{~h}$ with secondary antibodies $(0.5 \%$ biotinylated anti-mouse or anti-rabbit in PBS). Slides were then washed with PBS, incubated with the $\mathrm{ABC}$ complex for $1 \mathrm{~h}$ at $24^{\circ} \mathrm{C}$, 


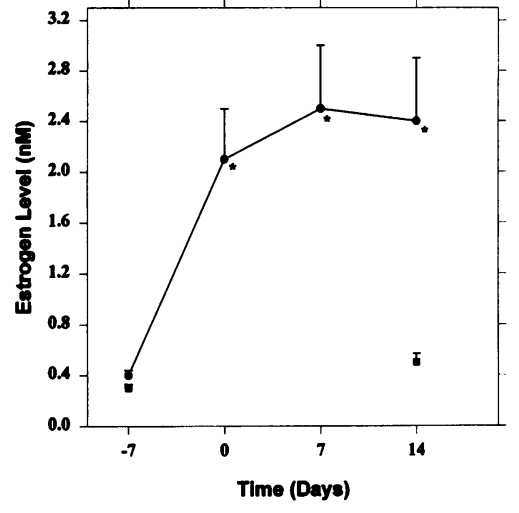

Figure 1. Estrogen Levels in $-\mathrm{E} 2(\boldsymbol{\square})$ and $+\mathrm{E} 2$ (•) mice. Serum samples from tail bleeds of five to nine mice were collected at the times shown and estrogen levels were measured by EIA (mean \pm SEM). The mean levels of $2.1-2.5$ $\mathrm{nM}$ achieved and maintained throughout the study in the $+\mathrm{E} 2$ group are comparable to levels in normal, nonovariec-

tomized $\mathrm{C} 57 \mathrm{BL} / 6 \mathrm{~J}$ mice and premenopausal human females. ( $P$ $<0.05$ vs Day -7 value)

and developed with $3.3^{\prime}$-diaminobenzidine. The slides were counterstained with filtered $10 \%$ modified Harris hematoxylin, and dehydrated with a series of alcohols ( 95 and $100 \%$ ) and xylene for 10 min each, coverslipped, and examined. For smooth muscle actin immunostaining, 3-amino-9 ethylcarbazide in $\mathrm{N}, \mathrm{N}$-dimethylformamide was used to develop the horseradish peroxidase, after which the slides were dried and coverslipped. Photography was performed on a microscope (AH2; Olympus Corp., Lake Success, NY) using color film (Kodak 200; Eastman Kodak Co., Rochester, NY).

Two independent and blinded observers quantified BrdU-stained cells and factor VIII related antigen-positive cells. BrdU-positive cells in the media and intima were counted, as were those cells in the innermost portion of the intima that were directly adjacent to the lumen (luminal). The total cell count in each section was defined as the sum of intimal- and medial-labeled cells. Smooth muscle cells were identified by smooth muscle cell $\alpha$-actin staining in parallel carotid sections.

Calculations and statistics. All values are expressed as mean \pm SEM When only two groups were compared, differences were assessed by the unpaired Student's $t$ test. When multiple comparisons were required, between group differences were first tested for by ANOVA. When the ANOVA demonstrated significant differences between groups, individual mean differences were analyzed by the Newman-Keuls method. For all statistical analyses, a $P$ value $<0.05$ was considered significant.

\section{Results}

Estrogen levels and dosing. Pilot studies showed basal E2 levels in normal, nonovariectomized C57BL/6J mice were 0.4-0.9 $\mathrm{nM}$, and those in normal premenopausal human females were $0.9 \mathrm{nM}$. In these pilot studies, replacement of ovariectomized C57BL/6J mice with $100 \mu \mathrm{g} \mathrm{E2/d}$ led to steady state E2 levels that closely approximated these values. In separate studies, use of this E2 regimen for $3 \mathrm{wk}$ in ovariectomized C57BL/6J mice did not significantly change circulating total cholesterol (TC) or triglycerides (TG) levels of animals in comparison to -E2 (vehicle control) animals. Furthermore, there were no differences in lipid levels between the $+\mathrm{E} 2$ and $-\mathrm{E} 2$ groups and intact, nonovariectomized C57BL/6J mice ( $P=$ NS by ANOVA for all comparisons; data not shown). The main study therefore was undertaken using $100 \mu \mathrm{g} \mathrm{E2/d}$ for the E2 replacement group. The estrogen levels in the -E2 group remained low and unchanged throughout the main study (day $-7,-\mathrm{E} 2$ $=0.3 \pm 0.03 \mathrm{nM}$; day $14,-\mathrm{E} 2=0.5 \pm 0.08 \mathrm{nM}, P=\mathrm{NS}$ ) (Fig. 1). In the estrogen-replaced animals, a fourfold increase in circulating E2 levels was noted after seven days (day $-7,+\mathrm{E} 2$
$=0.4 \pm 0.07 \mathrm{nM}$; day $0,+\mathrm{E} 2$ level $=2.1 \pm 0.4 \mathrm{nM}$; day -7 vs day $0, P<0.001$ ), and this level of E2 persisted unchanged throughout the duration of the experiment (day 14, +E2 $=2.4 \pm 0.5 \mathrm{nM}$, day 0 vs day $14, P=\mathrm{NS}$; Fig. 1 ).

Morphometry. Fig. 2 compares the intimal and medial areas and their ratios for uninjured (NL) and injured (-E2 and +E2) vessels 2 wk after injury. Compared to the normal vessel, injury induced a marked increase in both intimal and medial area in the $-\mathrm{E} 2$ group arteries, but not in the +E2 group arteries (Fig. 2; compare with Fig. 4, which demonstrates representative sections and stains for these analyses and for those discussed below). Specifically, carotid intimal area was increased in the -E2 group compared to carotids from NL animals (-E2 $\left.=57 \pm 34 \mathrm{~mm}^{2} \times 10^{-4}, \mathrm{NL}=7 \pm 2 \mathrm{~mm}^{2} \times 10^{-4} ; P<0.05\right)$. E2 administration completely inhibited the increase in intimal area due to injury $\left(+\mathrm{E} 2=9.6 \pm 2 \mathrm{~mm}^{2} \times 10^{-4}, P=\mathrm{NS}\right.$ vs NL and $P<0.05$ vs - E2; Fig. 2). Medial areas in the injured arteries from -E2 animals also demonstrated significant increases in comparison to the arteries from the NL group (medial area: $-\mathrm{E} 2=38 \pm 4 \mathrm{~mm}^{2} \times 10^{-3} ; \mathrm{NL}=27 \pm 2 \mathrm{~mm}^{2} \times 10^{-3}, P$ $<0.05)$. However, in the injured carotid arteries from mice receiving E2 replacement, the medial area remained low and was not different than that of normal arteries, (+E2 medial area $=25 \pm 2 \mathrm{~mm}^{2} \times 10^{-3}, P=\mathrm{NS}$ vs NL and $P<0.05$ vs $-\mathrm{E} 2$; Fig. 2). The intimal/medial area (I/M) ratio also increased in the $-\mathrm{E} 2$ vessels, but the $\mathrm{I} / \mathrm{M}$ ratios for the groups did not reach statistical significance ( $P=0.07$ by ANOVA). Uninjured vessels $(\mathrm{NL})$ from animals that received vehicle alone and those that received estrogen replacement were indistinguishable both by appearance and by all morphometric criteria measured (data not shown). Intimal and medial thickness measurements also were made in all arterial sections to quantitate the vascular injury response by a second, independent method. In all cases these values paralleled the results described above, and similarly demonstrated highly significant suppression of the carotid artery injury response in mice receiving estrogen replacement (data not shown). A total of five of the injured carotids had clear evidence of thrombosis in situ, but no differences in the number of vessels demonstrating thrombosis were observed between the animals receiving estrogen replacement $(n=2)$ and those receiving vehicle alone $(n=3)$.

BrdU labeling of cells. BrdU labeling was used to quantitate the fraction of cells undergoing replication in the vessel wall throughout the two week period following vascular injury (Figs. 3,4 , and Table I). The total number of BrdU-labeled cells was greatly increased in the $-\mathrm{E} 2$ injured arteries in comparison to normal arteries. However, in comparison to the -E2 group, much less BrdU labeling was noted in the carotids from animals treated with estrogen (BrdU positive cells: $\mathrm{NL}=6.4 \pm 4.5 ;-\mathrm{E} 2$ $=113 \pm 26,+\mathrm{E} 2=40 \pm 3.7 ;-\mathrm{E} 2$ vs $\mathrm{NL}$ and $-\mathrm{E} 2$ vs $+\mathrm{E} 2 ; P$ $<0.05$; + E2 vs NL, $P=\mathrm{NS}$ ). BrdU labeling also was quantified in subregions of the vessel wall, including the media, intima and those cells directly adjacent to the lumen (luminal) (Fig. 3 and Table I). As shown in Fig. 3 and Table I, the increase in total BrdU-labeled cells in vessels from the -E2 group resulted from significant increases in cellular proliferation in both the media and intima (intimal and medial BrdU labeling in $-\mathrm{E} 2$, both $P<0.05$ vs NL). This increase was attenuated in the $+\mathrm{E} 2$ vessels for each subregion (intimal and medial BrdU labeling in $+\mathrm{E} 2$, both $P<0.05$ vs $-\mathrm{E} 2$ ). The medial BrdUlabeled cells in the $-\mathrm{E} 2$ vessels were identified largely as 

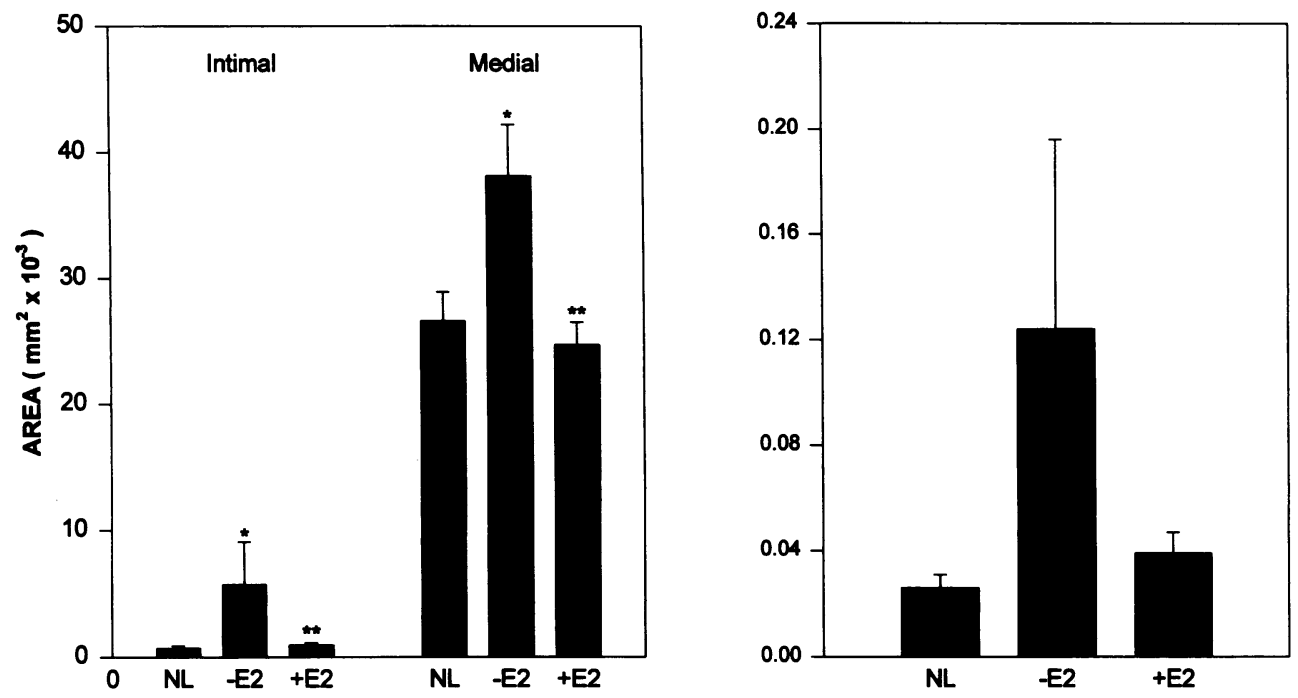

Figure 2. Intimal and medial areas in normal and injured vessels $14 \mathrm{~d}$ after injury. Intimal and medial areas, and the intimal/medial (I/ M) ratio were measured with computer-assisted quantitative morphometry by two independent and blinded observers in elastinstained sections of normal and injured carotids. For both intimal and medial areas, injury led to significant increases in the $-\mathrm{E} 2$ group $\left({ }^{*} P<0.05\right.$ vs NL), while estrogen replacement led to normalization of both measurements (+E2 group, $P=$ NS vs. NL for each). The intimal and medial areas of the $+\mathrm{E} 2$ group were significantly less than the $-E 2$ group $(* * P<0.05)$.

smooth muscle cells, both morphologically and by staining for $\alpha$-actin in parallel sections (data not shown). However, in the $+\mathrm{E} 2$ vessel sections, the majority ( $84 \%$ [34/40 cells]) of BrdUlabeled cells were confined to the intima, and this labeling proved to be essentially all in cells adjacent to the lumen (Table). To examine which of these luminal cells were endothelial cells, parallel sections were stained for factor VIII-related antigen, which confirmed that most of the BrdU-labeled luminal cells were endothelial cells (Table I). By day 14 after injury, when these analyses were performed, no differences in the ex-

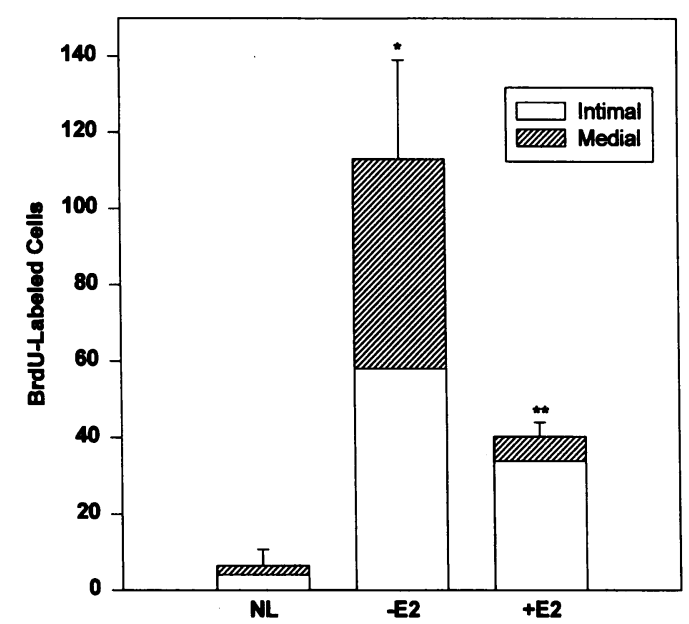

Figure 3. Total BrdU-labeled cells in normal and injured arteries $14 \mathrm{~d}$ after injury. Animals received BrdU by constant infusion via an implanted osmotic minipump for the $14 \mathrm{~d}$ after injury. Total BrdU-labeled cells were quantitated in each cross section by two independent and blinded observers by counting and summing intimal and medial BrdUlabeled cells. The total number of BrdU-labeled cells increased markedly after injury in carotid arteries from animals receiving vehicle alone (-E2), but this response was significantly attenuated in the +E2 group arteries. ${ }^{*} P<0.05$ vs $\mathrm{NL} ;{ }^{*} P<0.05$ vs $-\mathrm{E} 2$ and $P=$ NS vs NL. tent of factor VIII-related antigen positive cells was detected between the $-\mathrm{E} 2$ and $+\mathrm{E} 2$ vessels.

\section{Discussion}

This study has three principal findings: $(a)$ in ovariectomized C57BL/6J mice, carotid injury results in significant increases in vascular intimal and medial area and thickness; $(b)$ replacement of estrogen to nanomolar (physiologic or near-physiologic) levels in these animals significantly suppresses the vascular injury response for each of these parameters; and (c) smooth muscle cell proliferation over the $14 \mathrm{~d}$ after injury also is significantly suppressed by estrogen in this model.

Estrogen dosing in this experiment was determined empirically, using pilot studies to determine E2 doses that achieve steady state concentrations of E2 in the low nanomolar range. This level of E2 was sought based on measured levels of E2 in premenopausal women and normal, nonovariectomized mice in the pilot studies, and on published E2 levels for human females, and for C57BL/6J mice (reviewed in reference 26). The results of application of the carotid injury model to ovariectomized C57BL/6J mice reported here are comparable to those first reported for this model in normal Swiss Webster mice (29). The current study uses the original model to study an intervention, and adds to the model both quantitative morphometric analyses and BrdU labeling to measure cell proliferation. The BrdU data demonstrate a virtual absence of medial cell proliferation in the injured arteries from the estrogen-treated group (Fig. 3 and Table I) and support the conclusion that estrogenmediated inhibition of smooth muscle cell proliferation was marked. BrdU-labeling in the $+\mathrm{E} 2$ vessels was essentially all due to endothelial cell proliferation, which likely represents reendothelialization. These data also show that endothelial regrowth was extensive in both $-\mathrm{E} 2$ and $+\mathrm{E} 2$ vessels, and that no difference in the extent of endothelial regrowth was apparent between these groups by day 14 . However, the present study does not address whether the rate of endothelial regrowth differed in injured vessels from the two groups. 

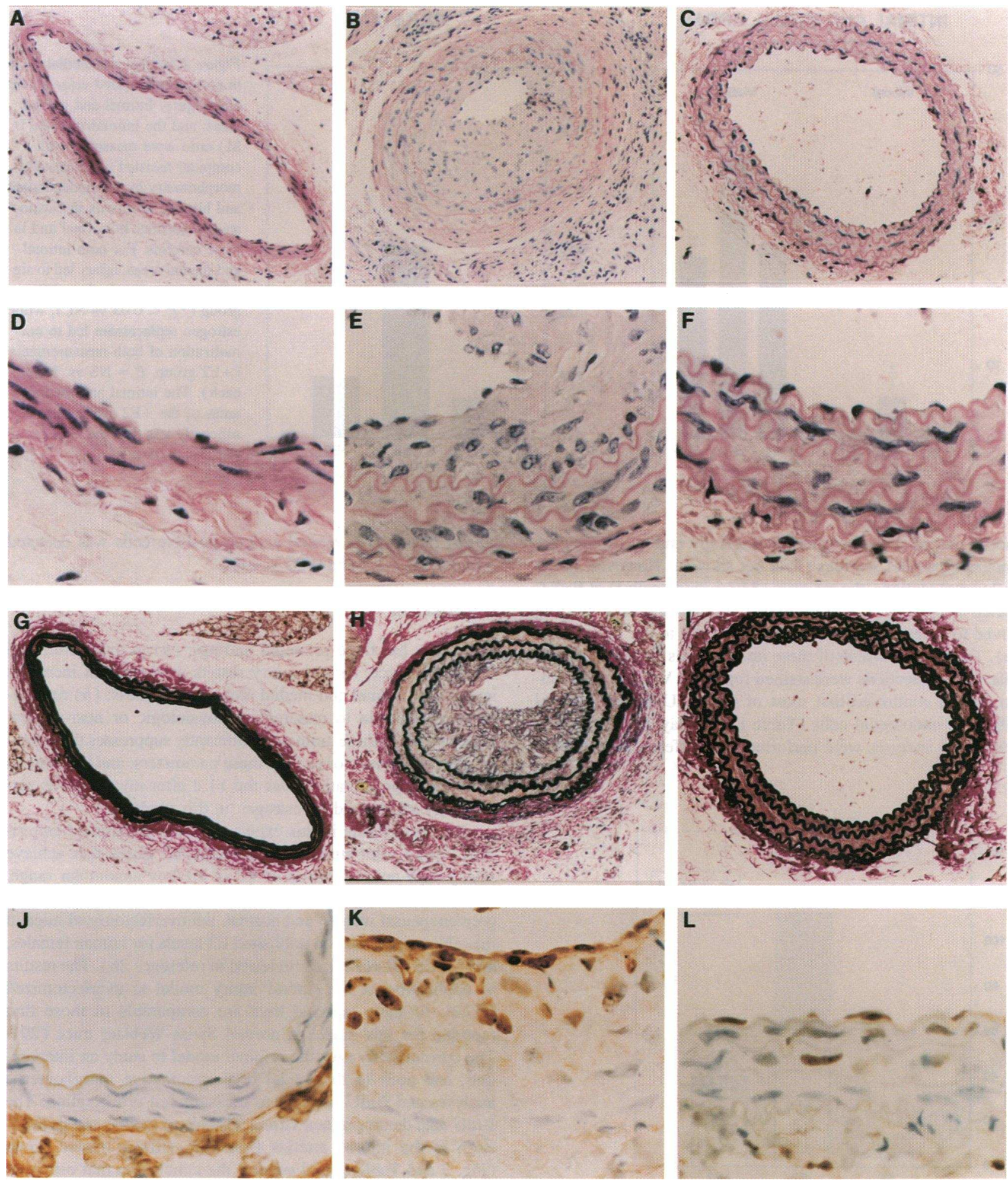

Figure 4. Photomicrographs of tissue specimens from normal and injured vessels $14 \mathrm{~d}$ after injury. $(A, D, G$, and $J)$ Normal; $(B, E, H$, and $K)$ vehicle treated (-E2); $(C, F, I$, and $L)$ Estrogen treated (+E2). Hematoxylin and eosin staining is shown in panels $A-C($ low power $=\times 200)$ and $D-F$ (high power $=\times 400$ ). Elastin staining is shown in panels $G-I$. Immunohistochemical staining for BrdU is shown in panels $J-L$.

Estrogen is thought to decrease atherosclerosis by both systemic effects and direct effects on the vessel wall. Although the mechanism(s) by which estrogen suppresses the vascular response-to-injury is not addressed by the present experiments, systemic effects on lipoproteins and coagulation pathway proteins in the present study were likely minimal due to the short 
Table 1. BrdU-labeled and Factor VIII-related Antigen-positive Cells

\begin{tabular}{lccccc}
\hline & \multicolumn{4}{c}{ BrdU labeling } & $\begin{array}{c}\text { Factor VIII- } \\
\text { related antigen- } \\
\text { positive cells }\end{array}$ \\
\cline { 2 - 5 } & Total & Medial & Intimal & Luminal & \\
\hline $\mathrm{NL}$ & $6.4 \pm 4.5$ & $2.3 \pm 1.5$ & $4.1 \pm 3.0$ & $3.8 \pm 2.7$ & $35.9 \pm 3.5$ \\
-E2 & $113 \pm 26^{*}$ & $55.0 \pm 19.7^{*}$ & $58.1 \pm 7.9^{*}$ & $42.5 \pm 6.5^{*}$ & $46.3 \pm 8.2$ \\
$+\mathrm{E} 2$ & $40.3 \pm 3.7^{\ddagger}$ & $6.4 \pm 2.3^{\ddagger}$ & $33.9 \pm 3.0^{* \ddagger}$ & $33.8 \pm 3.0^{*}$ & $35.4 \pm 3.0$
\end{tabular}

Intimal includes all positive cells within the first internal elastic membrane. Luminal includes only the innermost intimal cells adjacent to the lumen. ${ }^{*} P<0.05$ vs $\mathrm{NL},{ }^{\ddagger} P<0.05$ vs $-\mathrm{E} 2$, all other comparisons not significant. Comparisons of groups were tested by ANOVA and individual mean differences were analyzed by the Newman-Keuls method.

duration of the study, the maintenance of a normal diet (27), and the absence of any effect of the estrogen regimen on lipid levels, which was confirmed by measuring total cholesterol and triglyceride levels. Direct estrogen effects on the vasculature of two general types have been reported (reviewed in reference 8): rapid, nongenomic effects on vascular tone, and genomic effects mediated by altered gene expression via the estrogen receptor, an estrogen-activated transcription factor that is present (16, 37-39) and functional $(17 \mathrm{a}, 38)$ in human and rat (40) vascular smooth muscle cells. Based on current models of atherosclerosis and restenosis after vascular injury $(41,42)$, the known effects of estrogen, and the data presented here, a number of mechanisms might contribute to the estrogen effects on the response-to-injury observed in the present study. These potential mechanisms include $(a)$ direct effects of estrogen on vascular smooth muscle cell proliferation (suggested previously in cell culture $[23,24]$ and animal studies $[9,18-22]) ;(b)$ inhibition of the synthesis and/or deposition of vascular matrix elements that contribute to lesion growth in injured vessels (4345); (c) an altered rate of re-endothelialization after injury $(17)$; and $(d)$ estrogen inhibition of the inflammatory response in the injured vessel wall (46).

This study was undertaken in C57BL/6J mice in part so that the mechanism of any effect noted might be studied next in C57BL/6J transgenic mice lacking the estrogen receptor (25, 47 ). These studies, now in progress, may allow a role for the estrogen receptor to be included or excluded in the effects of estrogen on the injury response noted in the present study. The findings in the present study also raise the possibility that physiologic levels of estrogen replacement may have a therapeutic role in prophylaxis against restenosis after percutaneous angioplasty of coronary or peripheral vessels.

\section{Acknowledgments}

We gratefully acknowledge Jose Ordovas and Ernie Schaefer for their help with the lipid measurements, and we thank Patricia Nayak for expert preparation of the manuscript.

This work was supported in part by an National Institutes of Health Clinical Investigator Development Award (HL-03086) to R. H. Karas.

\section{References}

1. Barrett-Connor, E. and T. L. Bush. 1991. Estrogen and coronary heart disease in women. J. Am. Med. Assoc. 265:1861-1867.
2. Wenger, N. K., L. Speroff, and B. Packard. 1993. Cardiovascular health and disease in women. N. Engl. J. Med. 329:247-256.

3. Grady, D., S. M. Rubin, D. B. Petitti, C. S. Fox, D. Black, B. Ettinger, V. L. Ernster, and S. R. Cummings. 1992. Hormone therapy to prevent disease and prolong life in postmenopausal women. Ann. Intern. Med. 117:1016-1037.

4. Stampfer, M. J., G. A. Colditz, W. C. Willett, J. E. Manson, B. Rosner, F. E. Speizer, and C. H. Hennekens. 1991. Postmenopausal estrogen therapy and cardiovascular disease. N. Engl. J. Med. 325:756-762.

5. Gruchow, H. W., A. J. Anderson, J. J. Barboriak, and K. A. Sobocinski. 1994. Postmenopausal use of estrogen and occlusion of coronary arteries. Am. Heart J. 115:954-963.

6. Nabulsi, A. A., A. R. Folsom, A. White, W. Patsch, G. Geiss, K. K. Wu, and M. Szklo. 1993. Association of hormone-replacement therapy with various cardiovascular risk factors in postmenopausal women. N. Engl. J. Med. 328:10691075.

7. Clarkson, T. B., M. S. Anthony, and K. P. Klein. 1994. Effects of estrogen on arterial wall structure and function. Drugs. 47(Suppl. 2):42-51.

8. Mendelsohn, M. E., and R. H. Karas. 1994. Estrogen and the blood vessel wall. Curr. Opin. Cardiol. 9:619-626.

9. Williams, J. K., M. R. Adams, and H. S. Klopfenstein. 1990. Estrogen modulates responses of atherosclerotic coronary arteries. Circulation. 81:16801687.

10. Williams, J. K., M. R. Adams, D. M. Herrington, and T. B. Clarkson. 1992 Short-term administration of estrogen and vascular responses of atherosclerotic coronary arteries. J. Am. Coll. Cardiol. 20:452-457.

11. Reis, S. E., S. T. Gloth, R. S. Blumenthal, J. R. Resar, H. A. Zacur, G. Gerstenblith, and J. A. Brinker. 1994. Ethinyl estradiol acutely attenuates abnormal coronary vasomotor responses to acetylcholine in postmenopausal women. Circulation. 89:52-60.

12. Gilligan, D. M., A. A. Quyyumi, R. O. Cannon, III, G. B. Johnson, and W. H. Schenke. 1994. Effects of physiological levels of estrogen on coronary vasomotor function in postmenopausal women. Circulation. 89:2545-2551.

13. Hayashi, T., J. M. Fukuto, L. J. Ignarro, and G. Chaudhuri. 1992. Basal release of nitric oxide from aortic rings is greater in female rabbits than in male rabbits: implications for atherosclerosis. Proc. Natl. Acad. Sci. USA. 89:1125911263.

14. Conrad, K. P., G. M. Joffe, H. Kruszyna, R. Kruszyna, L. G. Rochelle, R. P. Smith, J. E. Chavez, and M. D. Mosher. 1993. Identification of increased nitric oxide biosynthesis during pregnancy in rats. FASEB (Fed. Am. Soc. Exp. Biol.) J. 7:566-571.

15. Weiner, C. P., I. Lizasoain, S. A. Baylis, R. G. Knowles, I. G. Charles, and S. Moncada. 1994. Induction of calcium-dependent nitric oxide synthases by sex hormones. Proc. Natl. Acad. Sci. USA. 91:5212-5216.

16. Horwitz, K. B., and L. D. Horwitz. 1982. Canine vascular tissues are targets for androgens, estrogens, progestins, and glucocorticoids. J. Clin. Invest. 69:750-759

17. Morales, D. E., K. A. McGowan, D. S. Grant, S. Maheshwari, D. Bhartiya, M. C. Cid, H. K. Kleinman, and W. Schnaper. 1995. Estrogen promotes angiogenic activity in human umbilical vein endothelial cells in vitro and in a murine model. Circulation. 91:755-763.

17a. Koike, H., R. H. Karas, W. E. Baur, and M. E. Mendelsohn. 1996. Differential display PCR identifies nucleophosmin as an estrogen-regulated gene in human vascular smooth muscle cells. J. Vasc. Surg. In press.

18. Stamler, J., R. Pick, and L. N. Katz. 1953. Prevention of coronary atherosclerosis by estrogen-androgen administration in the cholesterol-fed chick. Circ. Res. 1:94-98.

19. Moskowitz, M. S., A. A. Moskowitz, W. L. Bradford, and R. W. Wissler. 1956. Changes in serum lipids and coronary arteries of the rat in response to estrogens. Arch. Pathol. 61:245-263.

20. Constantinides, P., N. Gutmann-Auersperg, D. Hospes, and K. Williams. 1962. Estradiol and prednisone in rabbit atherosclerosis. Arch. Pathol. 73:277280.

21. Rhee, C. Y., T. H. Spaet, M. B. Stemerman, F. Lajam, and H. H. Shiang. 1977. Estrogen suppression of surgically induced vascular intimal hyperplasia in rabbits. J. Lab. Clin. Med. 90:77-84.

22. Foegh, M. L., B. S. Khirabadi, T. Nakanishi, R. Vargas, and P. W Ramwell. 1987. Estradiol protects against experimental cardiac transplant atherosclerosis. Transplant. Proc. 19:90-95.

23. Fischer-Dzoga, K., R. Wissler, and D. Vesselinovitch. 1983. The effect of estradiol on the proliferation of rabbit aortic medial tissue cells induced by hyperlipemic serum. Exp. Mol. Pathol. 39:355-363.

24. Vargas, R., B. Wroblewska, A. Rego, J. Hatch, and P. W. Ramwell. 1993. Oestradiol inhibits smooth muscle cell proliferation of pig coronary artery. $\mathrm{Br}$. $J$. Pharmacol. 109:612-617.

25. Lubahn, D. B., J. S. Moyer, T. S. Golding, J. F. Couse, K. S. Korach, and O. Smithies. 1993. Alteration of reproductive function but not prenatal sexual development after insertional disruption of the mouse estrogen receptor gene Proc. Natl. Acad. Sci. USA. 90:11162-11166. 
26. Barkley, M. S., I. I. Geschwind, and G. E. Bradford. 1979. The gestational pattern of estradiol, testosterone and progesterone secretion in selected strains of mice. Biol. Reprod. 20:733-738.

27. Aubert, R., D. Perdereau, M. Roubiscoul, J. Herzog, and D. Lemonnier 1988. Genetic variations in serum lipid levels of inbred mice and response to hypercholesterolemic diet. Lipids. 23:48-54.

28. Otto, J., J. M. Ordovas, D. Smith, D, van Dongen, R. Nicolosi, and E. J. Schaefer. 1995. Lovastatin inhibits diet induced atheroslcerosis in F1B golden syrian hamsters. Atherosclerosis. 114:19-28.

29. Lindner, V., J. Fingerle, and M. A. Reidy. 1993. Mouse model of arteria injury. Circ. Res. 73:792-796.

30. Rasband, W. 1995. NIH Image Analysis Program, U.S. National Institutes of Health. Available from the Internet by anonymous ftp from Zippy.nimh.nih.gov or on floppy disk from NTIS, 5285 Port Royal Road, Springfield, VA 22161, Part No. PB93-504868

31. Gratzner, H. G. 1982. Monoclonal antibody to 5-bromo- and 5-iododeoxyuridine: a new reagent for detection of DNA replication. Science (Wash. DC). 218:474.

32. Tischler, A. T. 1995. Triple immunohistochemical staining for bromodeoxyuridine and catecholamine biosynthetic enzymes using microwave antigen retrieval. J. Histochem. Cytochem. 43:1-4.

33. Mukai, K., J. V. Schollmeyer, and J. Rosai. 1981. Immunohistochemica localization of actin: applications in surgical pathology. Am. J. Surg. Pathol. 5:91-97.

34. Nadji, M., M. S. Gonzales, and A. Castro. 1980. Factor VIII-related antigen: an endothelial cell marker. Lab. Invest. 42:139.

35. Guesdon, J. L., T. Ternynck, and S. Avrameas. 1979. The use of avidinbiotin interaction in immunoenzymatic techniques. J. Histochem. Cytochem. 27:113.

36. Shi, S. R., M. E. Key, and K. L. Kalra. 1991. Antigen retrieval in formalinfixed, paraffin embedded tissues: an enhancement method for immunohistochemical staining based on microwave heating of tissue sections. J. Histochem. Cytochem. 39:741.
37. Shain, S. A., A. L. Lin, and H. C. McGill, Jr. 1988. Steroid receptors in the cardiovascular system: potential physiologic significance. In Steroid Receptor and Disease: Cancer, Bone and Circulatory Disorders. P. J. Sheridan, K. Blum, and M. C. Trachtenberg, editors. Marcel Dekker, Inc., New York. 547-567.

38. Karas, R. H., B. L. Patterson, and M. E. Mendelsohn. 1994. Human vascular smooth muscle cells contain functional estrogen receptor. Circulation 89:1943-1950.

39. Losordo, D. W., M. Kearney, E. A. Kim, J. Jekanowski, and J. M. Isner. 1994. Variable expression of the estrogen receptor in normal and atherosclerotic coronary arteries of premenopausal women. Circulation. 89:1501-1510.

40. Bayard, F., S. Clamens, F. Meggetto, N. Blaes, G. Delsol, and J.-C. Faye. 1995. Estrogen synthesis, estrogen metabolism, and functional estrogen receptors in rat arterial smooth muscle cells in culture. Endocrinology. 136:1523-1529.

41. Ross, R. 1993. The pathogenesis of atherosclerosis: a perspective for the 1990s. Nature (Lond.). 362:801-809.

42. Lee, P. C., G. H. Gibbons, and V. J. Dzau. 1993. Cellular and molecular mechanisms of coronary artery restenosis. Coron. Artery Dis. 4:254-259.

43. Cembrano, J., M. Lillo, J. Val, and J. Mardones. 1960. Influence of sex difference and hormones on elastin and collagen in aorta of chickens. Circ. Res. 8:527-529.

44. Beldekas, J. C., B. Smith, L. C. Gerstenfeld, G. E. Sonenshein, and C Franzblau. 1981. Effects of $17 \beta$-estradiol on the biosynthesis of collagen in cultured bovine aortic smooth muscle cells. Biochemistry. 20:2162-2167.

45. Fischer, G. M., and M. L. Swain. 1985. Effects of estradiol and progesterone on the increased synthesis of collagen in atherosclerotic rabbit aortas. Atherosclerosis. 54:177-185.

46. Frazier-Jessen, M. R., and E. J. Kovacs. 1995. Estrogen modulation of JE/ monocyte chemoattractant protein-1 mRNA expression in murine macrophages. $J$. Immunol. 154:1838-1845.

47. Korach, K. S. 1994. Insights from the stidy of animals lacking functional estrogen receptor. Science (Wash. DC). 266:1524-1527. 